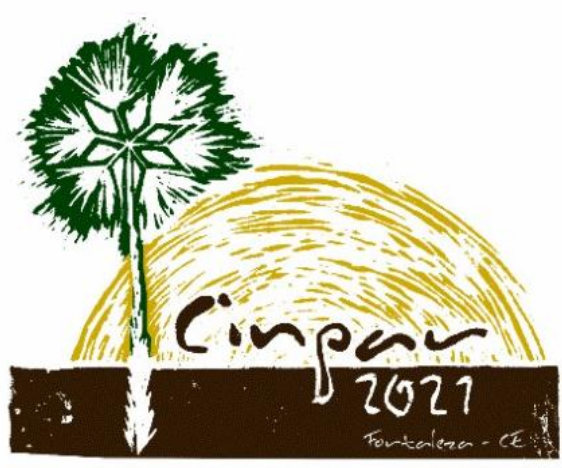

XVII Congresso Internacional sobre Patologia e

Reabilitação das Construções

XVII Congreso Internacional sobre Patología y Rehabilitación de las Construcciones

XVII International Conference on Pathology and Constructions Rehabilitation

FORTALEZA (Brasil), 3 a 5 de junho de 2021

https://doi.org/10.4322/CINPAR.2021.062

\title{
Estudo Diagnóstico em Residência Unifamiliar no Município de Fronteiras - Piauí
}

\section{Diagnostic Study in Single Family Residence in the Municipality of Fronteiras - Piaui}

\author{
Cicero Romário de Souza ${ }^{1}$, Andrea Alves da Silva ${ }^{1}$, Pablo Juan Lopes e Silva Santos ${ }^{2}$, \\ Rebeka Manuela Lobo Sousa ${ }^{2}$, Sávio Torres Melo ${ }^{1}$ \\ ${ }^{1}$ Centro Universitário do Piauí (UNIFAPI), Teresina - Piauí, Brasil, Departamento de Engenharia Civil, \\ cicero12romario@gmail.com, andreaalves1x@gmail.com,savio.melo@hotmail.com \\ ${ }^{2}$ Instituto Federal do Piauí (IFPI), Teresina - Piauí, Brasil, Departamento de Engenharia Civil, \\ pablojuan.engenhariacivil@gmail.com, rebekamanuela28@gmail.com
}

\begin{abstract}
Resumo: O processo de estudo diagnóstico tem início quando o caso em análise tem objetivo de entender os fenômenos e manifestações dinâmicas, neste primeiro momento e feito uma interpretação de cada subsídio alevantado, buscando entender de forma cronológica, como a estrutura funciona como foi construída e sua reação devido às manifestações patológicas como é, porque surgiram os problemas, todos esses dado contribuem para direcionamento e procura de informações para assim formular uma possível hipótese, podendo aplicar noções probabilística para formulação do diagnóstico. Com o intuito de buscar soluções e correções nas edificações faz se necessário realizar estudos diagnósticos, mas não é algo de imediato, pois devem atender um processo de análises e estudo para entender todo processo de evolução do caso, pois as manifestações podem ocorrer de uma maneira em certo momento e com outro aspecto completamente diferente em outra fase, que vai depender muito da sua evolução nesse sentido, este trabalho consiste num estudo de caso realizado em uma residência unifamiliar na cidade de Fronteiras Piauí, no qual se efetuou, com base nas orientações técnicas do IBAPE e ABNT, o preenchimento de todas as etapas de um diagnóstico visível a olho nu para identificar, todas as patologias, seguindo do prognostico, com um relatório, onde foram apresentadas todas as anomalias e falhas encontradas na residência, bem como suas medidas corretivas e saneadoras. Também, foi proposto um plano de manutenção adequado para correção das manifestações patológicas encontras na edificação em estudo.
\end{abstract}

Palavras-chave: Diagnostico, Prognostico, Inspeção Predial

\begin{abstract}
The diagnostic study process starts when the case under analysis aims to understand the dynamic phenomena and manifestations, in this first moment and an interpretation of each raised subsidy is made, trying to understand chronologically, how the structure works as it was built and their reaction due to the pathological manifestations as it is, because the problems arose, all of these data contribute to directing and searching for information to formulate a possible hypothesis, being able to apply probabilistic notions to formulate the diagnosis. In order to seek solutions and corrections in buildings, it is necessary to carry out diagnostic studies, but it is not something immediately, as they must attend a process of analysis and study to understand the entire process of evolution of the case, as the manifestations can occur in a way at a certain moment and with a completely different aspect in another phase, which will depend a lot on its evolution in this sense, this work consists of a case study carried out in a single-family residence in the city of Fronteiras Piauí, in which it was carried out, based on the guidelines IBAPE and ABNT techniques, filling in all stages of a diagnosis visible to the naked eye to identify, all pathologies, following the prognosis, with a report, where all the anomalies and flaws found in the residence were presented, as well as their measurements corrective and sanitary measures. Also, an adequate maintenance plan was proposed to correct the pathological manifestations found in the building under study.
\end{abstract}

Keyword: Diagnosis, Prediction, Building Inspection 


\section{Introdução}

A constante migração da população para as zonas urbanas proporciona vantagens para os municípios e aos habitantes, através de um aumento da construção de novas moradias em todas as regiões. A crescente implantação de novas residências unifamiliar possibilita o desenvolvimento da região através da origem de zonas comerciais, residenciais e turísticas, promovendo inúmeros benefícios como a geração de empregos e aumentando a movimentação nas ruas provocando um fortalecimento de um sentimento de vizinhança, pois com mais gentes nas ruas melhora a sensação de segurança além de mais dinheiro circulando na economia local.

As edificações devem ser projetadas com um padrão de qualidade, devendo ser construídas atendendo as necessidades dos usuários seguindo no mínimo três requisitos: resistência estrutural, desempenho adequado para o uso e durabilidade. Para garantir esse critério e necessário que haja além de um projeto adequado é primordial uma boa execução.

Com o passar do tempo essas edificações sofrem deteriorações de uso e de agentes externos como intemperismo, levando a casos extremos o comprometimento dessas estruturas podendo causar acidentes pela falta de manutenção dessas edificações, exigindo da engenharia civil buscar conhecimentos e tecnologias que possam ajudar a prevenir tais sinistros. Diante dessas anomalias faz-se indispensável à análise de um profissional engenheiro civil ou arquiteto devidamente habilitado pelos conselhos federal e regional previsto nas seguintes leis:

Lei de no 5.194 de 24 de dezembro de 1966,

Regula o exercício das profissões de Engenheiro, Arquiteto e EngenheiroAgrônomo, e dá outras providências.

Lei no 12.378 de 31 de dezembro de 2010,

Regulamenta o exercício da Arquitetura e Urbanismo; cria o Conselho de Arquitetura e Urbanismo do Brasil - CAU/BR e os Conselhos de Arquitetura e Urbanismo dos Estados e do Distrito Federal - CAUs; e dá outras providências.

A engenharia diagnóstica propõe estabelecer a qualidade total da edificação através do diagnóstico e prognóstico com o propósito de reduzir e tratar as manifestações patológicas, atuando em todas as fases da obra com ênfase maior no pós-obra, como os estudos das patologias, manutenções das edificações e correções necessárias. Neste contexto, este trabalho propõe fazer de acordo com as normas brasileiras existentes, ABNT E IBAPE um estudo diagnóstico e prognóstico de uma residência unifamiliar na cidade de Fronteiras Piauí.

As manifestações patológicas têm sido muito recorrentes nas edificações modernas seja ela de grande, médio ou pequeno porte, fato é, que tem tornado tema de discussão do mercado da construção civil. Os problemas patológicos vêm se tornando cada vez mais frequente, sabemos que todas as estruturas inclusive máquinas precisa de cuidados e manutenção periódica. Por isso é importante planejar e tomar cuidados para evitar complicações, até mesmo intervenções corretivas.

Nesse sentido, o estudo diagnóstico se torna importante, sobretudo pela as grandes incidências de casos recorrentes de manifestações patológicas, quantidade pequena de referências existentes e pesquisas relacionadas ao assunto, com o propósito de acrescentar informações para melhorar a análise diagnóstica.

O objetivo geral desta pesquisa consiste em realizar um estudo diagnostico em uma residência unifamiliar a fim de avaliar as patologias existentes, identificar possíveis falhas e explicações perante as normas brasileiras ABNT, IBAPE, por meio de um exame de todo o esquema construtivo de uma residência unifamiliar no município de Fronteiras no Piauí, a fim de identificar as principais patologias existentes na moradia, para assim fazer um esquema contendo as patologias existentes e por fim, apresentar um plano de manutenção corretivo e preventivo de acordo com as patologias presente na residência. 


\section{Esquema Normativo}

Tendo em vista, que norma ABNT NBR 16747 (2020), considera a inspeção predial sendo um processo que visa auxiliar na gestão das edificações, realizada com periodicidade e de forma regular contribui para mitigação de risco técnicos e econômicos que estão diretamente ligados ao desempenho das edificações. A atividade inspeção predial tem como principal objetivo constatar o estado e funcionamento e conservação da edificação, de seus sistemas e subsistemas, de forma a permitir um acompanhamento sistêmico do comportamento em uso ao longo da vida útil, para que seja mantida as condições mínimas necessárias, a segurança, habitabilidade e durabilidade da edificação.

Dessa forma, a engenharia diagnostica usa como um dos critérios avaliativos para identificação das patologias presente na edificação o laudo de inspeção, que por sua vez pode classificar o estado e o grau de risco da edificação, assim possibilitando as intervenções necessárias para conservação, manutenção e bom desempenho da mesma, conforme mostrado na Comissão de Estudo de Inspeção Predial. ABNT CB-02 140.02. (2013)

Segundo a norma do IBAPE (2012), a inspeção predial é dividida em três níveis, relacionada com a tipologia e o uso observado do imóvel a ser inspecionada, a complexidade dos sistemas construtivos. A tabela 1 mostra os níveis definidos na norma:

Tabela 1 - Classificação dos Níveis de Inspeção Predial

\begin{tabular}{|c|l|}
\hline $\begin{array}{c}\text { NIVEL } \\
\mathbf{1}\end{array}$ & $\begin{array}{l}\text { Corresponde à inspeção predial realizada em edificações de pequeno porte com baixa complexidade } \\
\text { técnica, de manutenção e de operação de seus elementos e sistemas construtivos empregada em } \\
\text { edificações com planos de manutenções muito simples. }\end{array}$ \\
\hline $\begin{array}{c}\text { NIVEL } \\
\mathbf{2}\end{array}$ & $\begin{array}{l}\text { Corresponde à inspeção Predial realizada em edificações de médio porte, considerando a complexidade } \\
\text { técnica, de manutenção e de operação de seus elementos e sistemas construtivos, de padrões construtivos } \\
\text { médios e com sistemas convencionais. }\end{array}$ \\
\hline $\begin{array}{c}\text { NIVEL } \\
\mathbf{3}\end{array}$ & $\begin{array}{l}\text { Corresponde à inspeção predial realizada em edificações consideradas de grande porte, com alta } \\
\text { complexidade técnica, de manutenção e operação de seus elementos e sistemas construtivos, de padrões } \\
\text { construtivos superiores e com sistemas mais sofisticados, empregada em edificações com vários } \\
\text { pavimentos ou com sistemas construtivos com automação. }\end{array}$ \\
\hline
\end{tabular}
Fonte: IBAPE, 2012

As anomalias normalmente estão relacionadas a defeitos construtivos e são caracterizadas pela a perdas do desempenho de um elemento, sistema ou subsistema e são divididas segundo norma ABNT NBR 16747 (2020) em:

- $\quad$ Endógena ou construtiva: quando a perda de desempenho decorre das etapas de projeto ou execução.

- Exógena: quando a perda de desempenho se relaciona a fatores externos a edificação provocada por terceiros.

- $\quad$ Funcional: quando a perda de desempenho de um elemento se relaciona com o envelhecimento natural consequentemente término da vida útil. ABNT NBR 16747 (ABNT 2020)

Em seguida a identificação e classificação das anomalias e falhas quanto à origem, determina-se o seu grau de risco avaliando os prejuízos causados aos usuários e a edificação. Também vale ressaltar, aos prejuízos referentes ao seu desempenho, estética e segurança. De acordo com a norma do IBAPE (2012) a tabela abaixo mostra como deve ser classificado o grau de risco.

Tabela 2 - Classificação de Riscos

\begin{tabular}{|c|l|}
\hline Crítico & $\begin{array}{l}\text { Quando a edificação apresenta risco de provocar danos contra a saúde e segurança das pessoas e do } \\
\text { meio ambiente, quando os sistemas e subsistemas não desempenham suas funções corretamente, } \\
\text { havendo a perda da funcionalidade causando possíveis paralisações, aumento excessivo de custo de } \\
\text { manutenção e correções, comprometimento da vida útil. }\end{array}$ \\
\hline Médio & $\begin{array}{l}\text { Quando a edificação apresenta risco de provocar a perda parcial de desempenho e funcionalidade de } \\
\text { seus sistemas e subsistemas, e deterioração precoce, apresentando menor risco a segurança do usuário. }\end{array}$ \\
\hline Mínimo & $\begin{array}{l}\text { Quando a edificação apresenta risco de causar pequenos prejuízos à estética ou atividade programável e } \\
\text { planejada, sem maiores danos aos seus sistemas e subsistemas, mantendo seu valor imobiliário. }\end{array}$ \\
\hline
\end{tabular}
Fonte: IBAPE, 2012

Após análise do risco e importante fazer um cronograma sequenciando de ações corretivas a serem tomadas, tendo em vista, o grau de risco e comprometimento das estruturas, devido as 
manifestações patológicas, é importante também estipular prazos para aplicar as meditas senadoras seguindo as recomendações técnicas para evita maiores danos as estruturas e risco de acidentes aos usuários.

\section{Metodologia}

Para o desenvolvimento do presente trabalho e atendimento de todos os objetivos, foi realizado usando as fontes normativas IBAPE (2012) ABNT NBR 16747 (2020), constituído um estudo diagnóstico visual em uma residência unifamiliar de 139,5 $\mathrm{m}^{2}$, localizada na Rua Projetada Nove S/N, Bairro Panorama em Fronteiras - Piauí, no qual foi realizado um levantamento "in loco", através da identificação das patologias de forma visual e fotografando para apresentar soluções propicias para os problemas diagnosticados compondo um prognóstico dessas anomalias. As imagens a seguir mostram perspectivas da residência juntamente com a sua planta baixa:

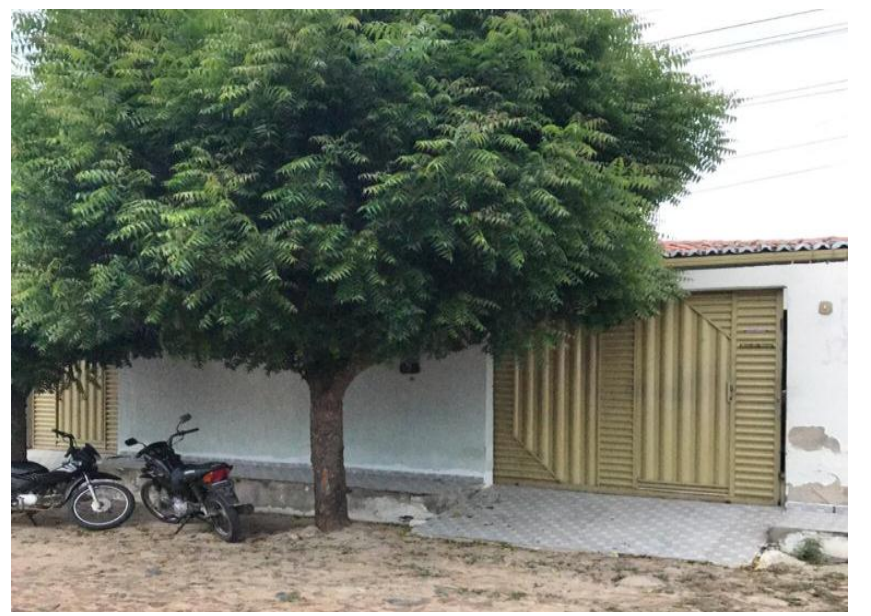

(a) Parte Externa da Casa

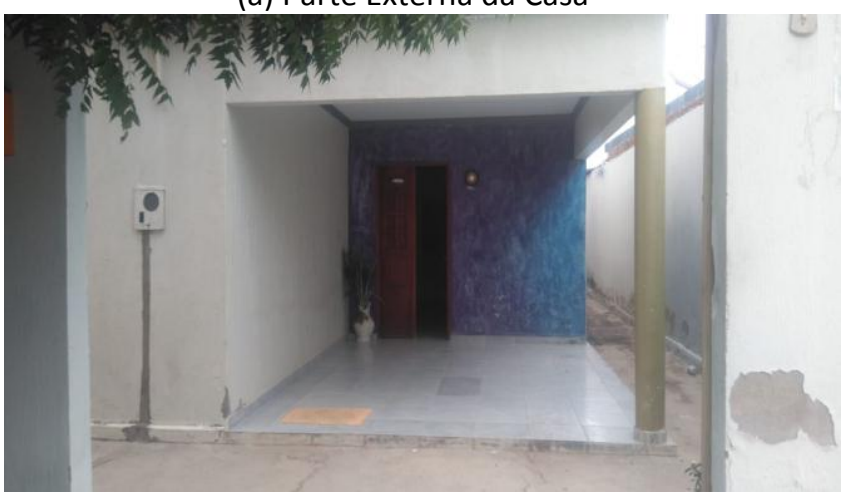

(b) Parte Interna da Casa

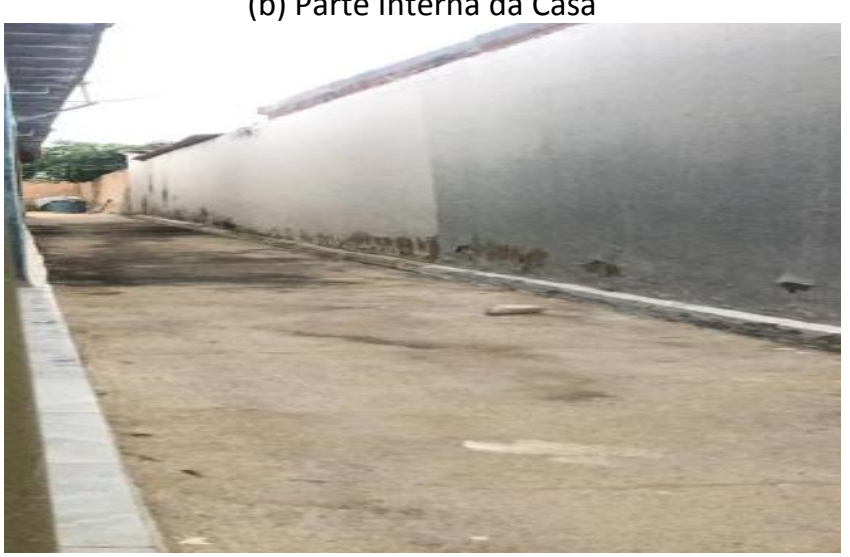

(c) Corredor Lateral da Casa

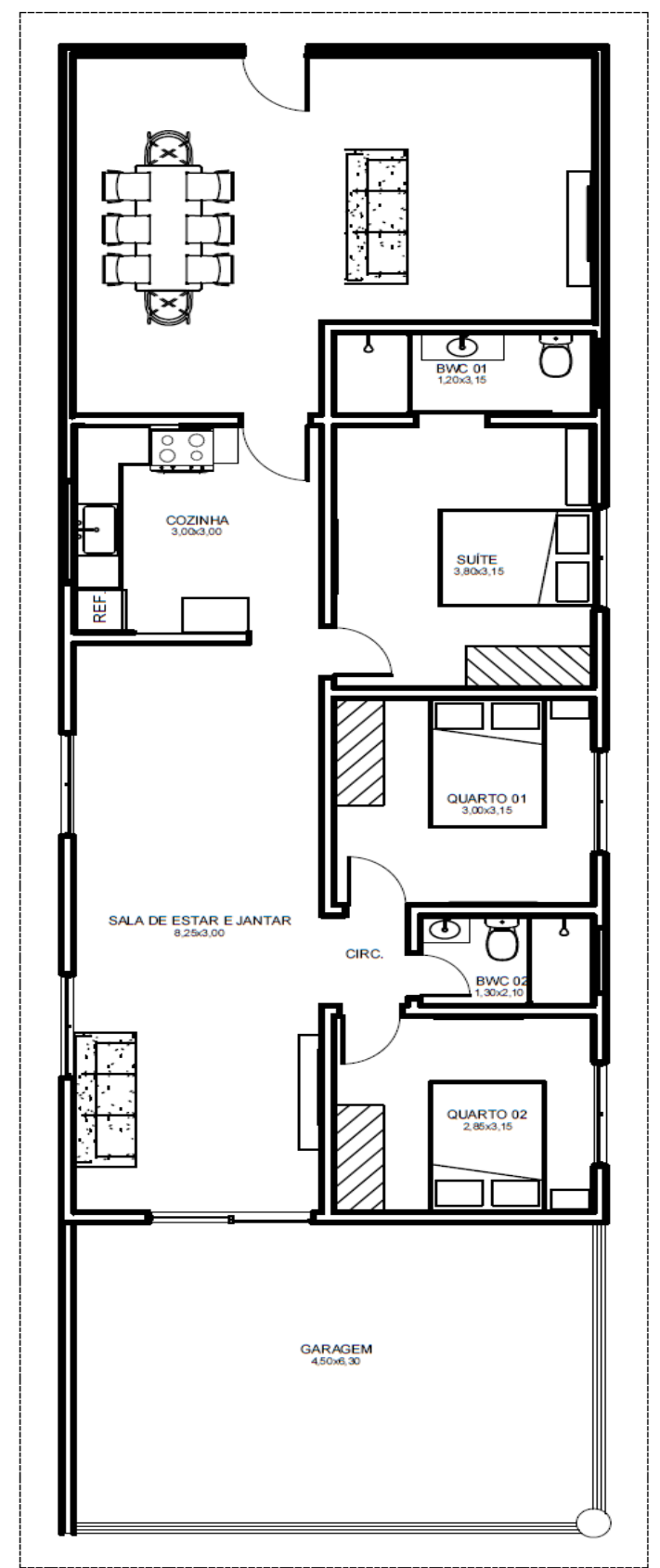

(b) Planta Baixa da Casa

Figura 1 - Residência Unifamiliar da Pesquisa

Fonte: Autores, 2020 
As etapas a seguir apresentam todos os procedimentos de um diagnóstico realizado na residência:

\section{Vistoria}

Os moradores da residência observaram a presença de algumas patologias existentes em diversos ambientes, no qual as preocupações se tornaram alarmantes para assim contatar profissionais técnicos, a fim de verificar as situações atuais da moradia. Para impedir qualquer pânico em uma construção recomenda realizar uma busca periódica de qualquer tipo de anomalia existente ou pelo menos início, para evitar danos futuros. Inicialmente, a realização de uma visita na residência para consultar as preocupações relatadas pelos moradores, dando início aos trabalhos de investigação, como também uma análise e decisões de ações prévias necessárias para aperfeiçoar o tempo e decidir como desenvolver os trabalhos de inspeção.

Diante disso, a solicitado ao proprietário da residência toda documentação legal, alvará de construção, projeto arquitetônico, estrutural, instalações elétricas e hidro sanitárias. O proprietário relata não ter mais à posse desses documentos, pois os mesmos foram perdidos, havendo à necessidade dos autores fazer um levantamento, mas detalhado para realizar a representação da planta baixa da residência no AutoCAD 2020, com o propósito de detalhar, identificar os locais de cada patologia e melhor entender o possível diagnóstico de cada anomalia encontrada.

\section{$>$ Inspeção}

Após os relatos dos moradores, a residência passou por uma investigação detalhada com o intuito de identificar e informar com clareza quais os procedimentos a prosseguir durante a inspeção. Na segunda visita, a inspeção visual consistiu em analisar todos os sistemas e subsistemas no interior da residência, e com isso a realização de entrevistas com os moradores para coletar dados como:

$>\quad$ Histórico da Residência: para assim saber o ano de construção, as reformas realizadas na residência;

$>$ Método Construtivo: com a intenção de delimitar quais as prováveis patologias que se adequem ao critério de execução realizado na residência;

$>$ Fatores Ambientais: as condições externas ao qual a moradia está submetida para saber durante o seu período de utilização;

Desta maneira, esses critérios auxiliam numa melhor compreensão para melhor entender as possíveis causas das patologias existentes no local, acompanhado de um registro fotográfico de todas as anomalias encontradas. Dessa forma foram vistoriados todos os ambientes da residência que podem apresentar algum risco aos usuários, com interesse de saber como proceder com as manutenções adequadas.

\section{$>$ Auditoria}

Após análise dos dados coletados "in loco", e nas entrevistas com os morados da residência, feito uma análise visual de todos sistemas e subsistemas da residência determinou-se as origens das não conformidades detectadas na residência.

Foi verificado que na residência, a falta de um planejamento de manutenção em seus sistemas e subsistemas tendo em vista que a última interversão foi realizada no ano de $2010 \mathrm{com}$ a conclusão da pintura e colocação do piso em revestimento cerâmico. As anomalias encontras podem ser classificadas como: anomalias endógenas, anomalias funcionais ou anomalias exógenas, ABNT NBR 16747 (2020).

\section{Perícia}

Nesta etapa, as informações referentes às patologias consistem em informar as origens juntamente com as causas e efeitos, a fim de mostrar o motivo da existência da patologia, além das consequências se não realizar as devidas manutenções. Logo após a finalização de todas etapas de investigação, vistoria, inspeção na residência obteve um diagnostico onde foram passadas todas as recomendações para cada sistemas e subsistemas da residência, apesentando a classificação das anomalias encontras conforme a ABNT NBR 16747 (2020). 


\section{Resultados e Discussões}

Diante dos dados coletados em campo, o modo como cada uma das anomalias se comporta mediante aos casos apresentados, com o intuito de realizar todos os procedimentos adequados para determinar e certificar o provável início de cada uma das patologias, conforme podem ser visualizados os seguintes aspectos a seguir:

- Destacamento do Reboco: Ocorre a separação do reboco da estrutura em diversos locais ou por completo, devido ao material utilizado (agregado, cimento etc.) ou a má execução (espessura do revestimento etc.), conforme mostra a figura $2 a, 2 b, 2 c$ e $2 d$, a localização juntamente com as fotos de cada um retiradas durante a inspeção;

- $\quad$ Eflorescência: Consiste na formação de manchas na superfície do revestimento devido à evaporação de sais dissolvidos em água, proveniente de ambientes quentes e úmidos, impurezas na areia etc. As imagens $2 \mathrm{e}, 2 \mathrm{f}, 2 \mathrm{~g}$ e $2 \mathrm{~h}$ mostram perfeitamente as situações dessa patologia na residência;

- $\quad$ Fissuras na diagonal: Pode ocorrer devido a micro movimentos ou de acomodação da edificação sobre o solo, conforme pode ser observado nas figuras $2 \mathrm{i}$ e $2 \mathrm{j}$;

- Trincas Horizontais e Diagonais: Ocorre por possíveis falhas na execução ou material de péssima qualidade, o mau dimensionamento de estruturas é um dos principais fatores (figura $2 \mathrm{k}$ e 2l);

- $\quad$ Fissuras diagonais em canto de janelas: Os esforços e tensões agem sobre as estruturas e paredes de uma construção em decorrência de seu próprio peso. No entanto, numa parede com portas e janelas os esforços se redistribuem, concentrando-se com mais intensidade sobre as quinas e o centro das aberturas (figura $2 \mathrm{~m}, 2 \mathrm{n}$ e 20 ).

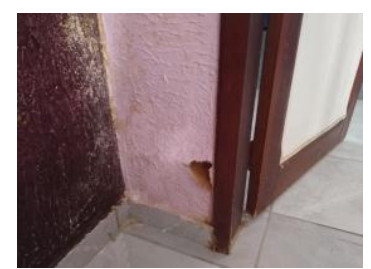

(a) Patologia A

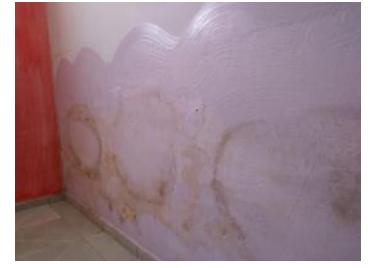

(e) Patologia E

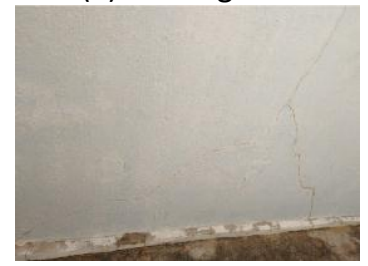

(i) Patologia I

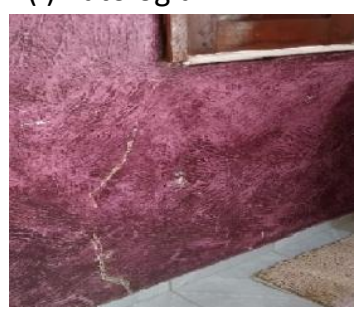

(m) Patologia M

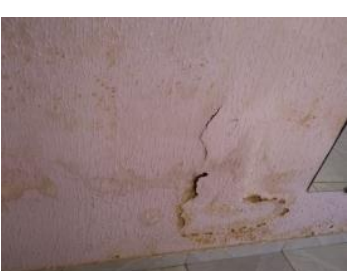

(b) Patologia B

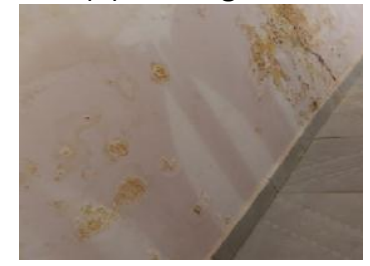

(f) Patologia F

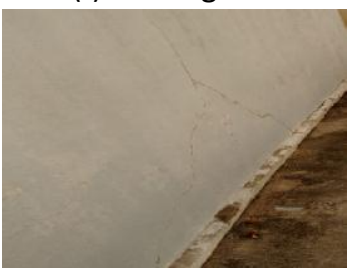

(j) Patologia J

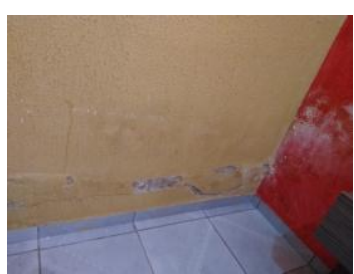

(c) Patologia C

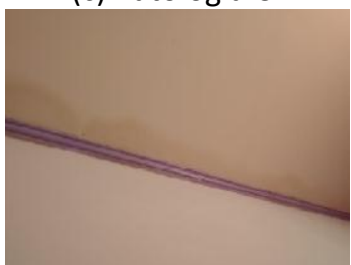

(g) Patologia G

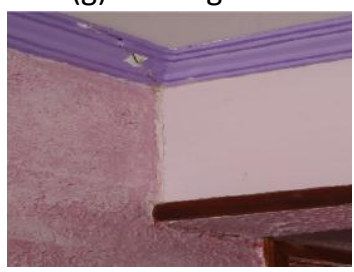

(k) Patologia K

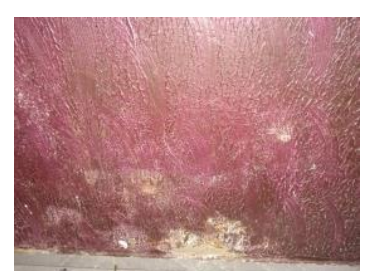

(d) Patologia D

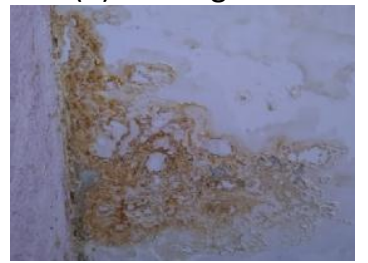

(h) Patologia $\mathrm{H}$

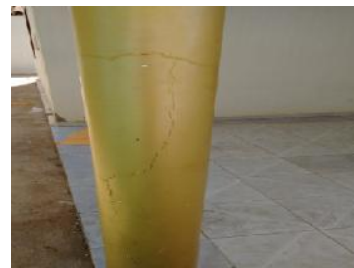

(I) Patologia L

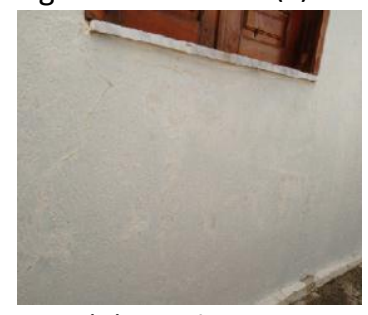

(n) Patologia N

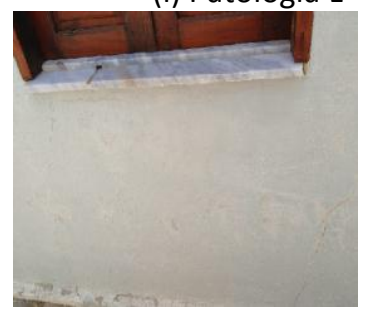

(o) Patologia $\mathrm{O}$

Figura 2 - Patologias Encontradas

Fonte: Autores, 2020

As anomalias e falhas encontradas ao longo da vistoria, inspeção e auditoria realizada na residência, foram descritas e classificadas de acordo com sua origem segundo a ABNT NBR 16747 (2020), analisado 
origem, causa e efeito, para aplicar medidas corretivas necessárias, para manter os sistemas e subsistemas da residência em funcionamento atendendo a necessidade dos usuários, a tabela 3 mostram isso de forma e clara.

Tabela 3 - Origem, Causa, Efeito

\begin{tabular}{|c|c|c|c|}
\hline Patologia & Origem & Causa & Efeito \\
\hline $\begin{array}{l}\text { Destacamento } \\
\text { do Reboco }\end{array}$ & Endógena & $\begin{array}{l}\text { Falha no processo executivo, uso de } \\
\text { matéria inadequado com presença de } \\
\text { matéria orgânica e ausência de } \\
\text { impermeabilizantes e chapisco }\end{array}$ & $\begin{array}{l}\text { Perda da proteção da alvenaria, } \\
\text { da estética e da camada de } \\
\text { pintura. }\end{array}$ \\
\hline Eflorescência & Endógena & $\begin{array}{l}\text { Falta de impermeabilizantes, presença } \\
\text { de goteiras. }\end{array}$ & $\begin{array}{l}\text { Perda da estética e do } \\
\text { substrato de reboco. }\end{array}$ \\
\hline $\begin{array}{c}\text { Fissuras na } \\
\text { diagonal }\end{array}$ & Endógena & $\begin{array}{l}\text { Erro de execução do projeto de } \\
\text { fundação, ausência de viga baldrame } \\
\text { ou bloco de fundação }\end{array}$ & $\begin{array}{l}\text { Perda da estética, porta de } \\
\text { entrada para agente externos } \\
\text { como água e organismos } \\
\text { orgânicos. }\end{array}$ \\
\hline $\begin{array}{l}\text { Trincas } \\
\text { Horizontais e } \\
\text { Diagonais }\end{array}$ & Endógena & $\begin{array}{l}\text { Uso de materiais inadequados, falhas } \\
\text { na execução, falta de amarração entre } \\
\text { viga e pilar, sobrepeso na estrutura, } \\
\text { falha de projetos estrutural ou } \\
\text { execução. }\end{array}$ & $\begin{array}{l}\text { Comprometimento da peça } \\
\text { estrutural porta de entrada } \\
\text { para agentes corrosivos, além } \\
\text { da estética. }\end{array}$ \\
\hline $\begin{array}{l}\text { Fissuras } \\
\text { diagonais em } \\
\text { canto de } \\
\text { janelas }\end{array}$ & Endógena & $\begin{array}{l}\text { Erro de execução, falta do elemento } \\
\text { estrutural vergas e contra vergas, } \\
\text { sobrecarregando a estrutura de } \\
\text { alvenaria. }\end{array}$ & $\begin{array}{l}\text { Perda da estética, porta de } \\
\text { entrada para agentes externos, } \\
\text { com a água comprometimento } \\
\text { da alvenaria de vedação. }\end{array}$ \\
\hline
\end{tabular}

Fonte: Autores, 2020

Diante das falhas e anomalias encontradas com suas respectivas classificações origem causa e efeito foram descritos os riscos e as medidas saneadoras juntamente com um plano de intervenções definido os prazos para aplicação de todas medidas corretivas, levando em consideração o grau de urgência e risco, segundo a norma do IBAPE (2012), tomando os devidos cuidados a quanto o risco eminente de acidentes aos usuários da residência devido as manifestações patológicas nas estruturas da residência, a tabela-4 a baixo mostra essa recomendações de forma resumida e clara.

Tabela 6 - Riscos, Medidas Saneadoras, Prazo/dias

\begin{tabular}{|c|l|l|c|c|}
\hline Patologia & Risco & \multicolumn{1}{|c|}{ Medidas Saneadoras } & Prazo/Dias \\
\hline $\begin{array}{c}\text { Destacamento } \\
\text { do Reboco }\end{array}$ & Médio & $\begin{array}{l}\text { Retirar todo reboco afetado, aplicação de impermeabilizantes } \\
\text { seguindo as recomendações dos fabricantes para evitar } \\
\text { infiltrações em áreas molhadas e externas, aplica chapisco, } \\
\text { aguardar o tempo de cura correto, emboco para regularização } \\
\text { e finalizar o reboco deixando a superfície lisa e plana. }\end{array}$ & 60 \\
\hline $\begin{array}{c}\text { Eflorescência } \\
\text { Fissuras na } \\
\text { diagonal }\end{array}$ & Médio & $\begin{array}{l}\text { Retirar todo material comprometido aplicação de } \\
\text { impermeabilizantes seguindo as recomendações dos } \\
\text { fabricantes para evitar infiltrações em ares molhadas e } \\
\text { externas, aplicação de uma nova camada de rebocos e pintura. }\end{array}$ & 90 \\
\hline $\begin{array}{c}\text { Trincas } \\
\text { Horizontais e } \\
\text { Diagonais }\end{array}$ & Crítico & $\begin{array}{l}\text { Fazer o projeto aquedo de fundação com o dimensionamento } \\
\text { correto para distribuição das cargas no solo, corrigindo a } \\
\text { estrutura existente. }\end{array}$ & 30 \\
\hline $\begin{array}{c}\text { Fissuras } \\
\text { diagonais em } \\
\text { canto de } \\
\text { janelas }\end{array}$ & Médio & $\begin{array}{l}\text { Colocarigindo as falhas existente. } \\
\text { remoção da área comprometidas para corrigir as fissuras } \\
\text { existente. }\end{array}$ & 30 \\
\hline
\end{tabular}

Fonte: Autores, 2020

Aplicação de todas as meditas saneadoras e corretivas tem urgência em sua execução, tendo em vista, o comprometimento de parte das estruturas de concreto principalmente no pilar de sustentação da 
garagem apresentando riscos consideráveis a ruptura, podendo causar maiores danos a residência e como também danos físicos aos usuários.

\section{Conclusão}

Nos últimos anos, ocorre um aumento da preocupação na segurança das edificações principalmente do poder público, perceptivos com a edição de leis e decretos municipais instituindo a obrigatoriedade da inspeção predial, em razão a recorrência de acidentes com edificações. Além deste fato, diante da crise econômica que o país enfrenta aliado a uma grande concorrência fez construtoras buscar tecnologias e soluções mais rápidas e ágeis, descuidando muitas vezes do principal quesito: a segurança, a mão de obra pouco qualificada também é um fator que tem contribuído muito para erros de execução em projetos, fatores esses que tem contribuído muito para surgir com mais frequências patologias nas edificações.

O presente trabalho teve como finalidade a realização de um estudo de caso de uma residência unifamiliar, comprido todos os requisitos para um diagnóstico, onde foram analisados os sistemas e subsistemas da residência passíveis de verificação a olho nu de acordo com a metodologia proposta pelo ABNT NBR 16747 (2020) e IBAPE (2012) identificando as patologias e falhas presentes. Em seguida, a identificação de um plano de manutenção, conforme a ordem de prioridade e os prazos indicados neste trabalho. Tendo em vista o resultado da análise de todas as patologias e falhas encontradas na residência, a prioridade esta relacionada a três: trincas no pilar, fissura nas esquadrias e comprometimento do reboco, pois a necessidade de realizar a correção das trincas no pilar e as fissuras nas esquadrias envolve o funcionamento estrutural e além dessas patologias encontradas, a não conformidades no reboco e pinturas compromete a estética da residência, segurança e conforto aos usuários.

Diante disso, considerando um número considerável de anomalias e falhas na residência, tendo em vista a falta de documentação solicitada, conclui-se a ausência de manutenções periódicas, provocando transtorno e desconforto os usuários além das preocupações devidos aos efeitos das patologias existentes. Portanto é imprescindível aos responsáveis pela residência a observação de todas as recomendações do diagnóstico e prognóstico proposto no presente trabalho, realizando todas as manutenções descritas, atentando aos prazos e prioridades, a fim de melhorar as condições de uso, conforto e segurança da residência. Também se torna necessário manter a periodicidade das vistorias e manutenções para atender de forma satisfatória e segura a necessidade de todos os moradores.

\section{Agradecimentos}

Agradecemos primeiro a Deus por ter nos mantido na trilha certa durante este projeto de pesquisa com saúde e forças para chegar até o final. Agradecemos também a instituição UNIFAPI pela oportunidade de cooperar com todos os nossos conhecimentos.

\section{Referências Bibliográficas}

ASSOCIAÇÃO BRASILEIRA DE NORMAS TÉCNICAS. NBR 16747: Inspeção Predial - Rio de Janeiro, 2020.

BRASIL: Lei de no5.194 de 24 de dezembro de 1966. Brasília: Palácio do Planalto,1966.

BRASIL: Lei de no12378 de 31 de dezembro de 2010. Brasília: Palácio do Planalto, 2010.

INSTITUTO DE ENGENHARIA. Diretrizes Técnicas de Engenharia Diagnóstica em Edificações. 2014. Disponível em: https://www.institutodeengenharia.org.br/site/wpcontent/uploads/2017/10/arqnot8482.pdf. Acesso em: 15 maio 2020.

NORMAS DE INSPEÇÃO PREDIAL. Segundo a norma de inspeção predial do IBAPE NACIONAL, Instituto Brasileiro de Avaliações e Perícias, 2012. 18 p. Disponível em: http://ibape-nacional.com.br/biblioteca/wpcontent/uploads/2012/12/Norma-de-Inspe\%C3\%A7\%C3\%A3o-Predial-IBAPE-Nacional.pdf. Acesso em: 22 jul. 2020.

SÃO PAULO. Comitê Brasileiro da Construção Civil. Ibape (ed.). CE-02:140.02: ABNT. 2012. Comissão de Estudo de Inspeção Predial. Disponível em: http://oquetenhoafazer.com.br/wpcontent/uploads/2017/08/Texto-base-projeto-de-Norma-Inspec\%CC\%A7a\%CC\%83o-predial-conceitosterminologia-crit...pdf. Acesso em: 10 mar. 2020. 